\title{
Design and Production of a Hermetic Bayonet Isolation Valve
}

\author{
Joel Fuerst \\ Fermi National Accelerator Laboratory \\ P.O. Box 500, Batavia, Illinois 60510
}

May 1993 


\section{Disclaimer}

This report was prepared as an account of work sponsored by an agency of the United States Government. Neither the United States Government nor any agency thereof, nor any of their employees, makes any warranty, express or implied, or assumes any legal liability or responsibility for the accuracy, completeness, or usefulness of any information, apparatus, product, or process disclosed, or represents that its use would not infringe privately owned rights. Reference herein to any specific commercial product, process, or service by trade name, trademark, manufacturer, or otherwise, does not necessarily constitute or imply its endorsement, recommendation, or favoring by the United States Government or any agency thereof. The views and opinions of authors expressed herein do not necessarily state or reflect those of the United States Government or any agency thereof. 


\title{
DESIGN AND PRODUCTION OF A HERMETIC BAYONET ISOLATION VALVE
}

\author{
Joel Fuerst \\ Fermi National Accelerator Laboratory* \\ P.O. Box 500, Batavia, IL 60510
}

\begin{abstract}
Fermilab is upgrading the Tevatron for lower temperature/higher beam energy operation. Portions of the satellite refrigeration system will operate below atmospheric pressure after the upgrade is complete. Contamination must be prevented by hermetically sealing the subatmospheric helium to air interfaces. Bayonet connections in the low pressure flow path require a reliable, leak tight isolation valve instead of the standard quarter turn ball valve. Design, development, and production of a new valve are described.
\end{abstract}

Keywords: Cryogenics, Subatmospheric, Hermetic, Valve

\section{INTRODUCTION}

Fermilab will upgrade its Tevatron accelerator(1) to a maximum beam energy of about $1.1 \mathrm{TeV}$. This is a $22 \%$ increase over the current maximum and represents a hard upper limit for several major accelerator systems including magnets, cryogenics, and power leads. This energy increase will be achieved by reducing the operating temperature of the accelerator's superconducting magnets by $21 \%$ (about one degree Kelvin). Lower temperatures allow higher currents in the magnet windings which create higher magnetic fields capable of directing higher energy beams.

Cold vapor compressors ${ }^{(2)}$ are used to draw a mild vacuum over the two phase helium refrigeration circuits of the magnet strings. This lowers the helium's boiling point which drops the magnet temperatures accordingly. Small leaks between the helium system and the atmosphere which were formerly a nuisance now become serious contamination threats since air is pulled into the system instead of helium leaking out. Captured air quickly solidifies and plugs lines, coats heat exchangers, and destroys rotating machinery. Much work has been done to upgrade or eliminate joints between subatmospheric helium circuits and the atmosphere.

Tevatron refrigerators are made up of several independent vacuum insulated components whose flow paths are connected by removable "U-tube" jumper lines. An in-house designed bayonet connection similar to those available from industry

* Operated by the Universities Research Association, Inc. for the U.S. Department of Energy. 
serves as the joint between components and the jumper tubes. These bayonets are made in a variety of sizes and consist of an insert at the end of the jumper which fits through an isolation valve into a housing connected to the component. The isolation valve typically used is a standard quarter turn ball valve. It is possible for these valves to leak through the packing or past other elastomer seals. This presents a contamination hazard for bayonets operating with subatmospheric helium. The low temperature upgrade requires two bayonet connections in the refrigerators to be hardened for subatmospheric service. These are located at the $\mathrm{CHL}^{(3)}$ transfer line supply/valve box joint and at the valve box/cold vapor compressor intake joint. In addition there are subatmospheric bayonet connections on the barrier boxes in the tunnel at D0. A total of about 60 hermetic isolation valves are needed to eliminate the possibility of contamination.

\section{DESIGN}

Appropriate designs were not available in the marketplace. In-house prototypes were constructed around commercial vacuum gate valves (Figure 1); however, these valves are not fit for internal pressure such as may be seen in this application. Although these units will nominally operate under vacuum conditions, they may see significant internal pressure when the cold equipment to which they are attached is disconnected and pressurizes to the relief point during warm up. A vacuum valve manufacturer proposed development of a custom gate-style valve suitable to the task. Unfortunately, costs were prohibitive. In-house efforts resulted in the design shown in Figure 2. A hinged "swing-check" style mechanism was selected for the valve action. A sealing disk rides on a hinged flap arm driven via a guided slot by a push-pull linkage. A purchased De-Sta-Co toggle with $180^{\circ}$ of lever travel and 3/4" of stroke swings the sealing disk through an $80^{\circ}$ arc. The sealing disk is spring loaded to allow a tight, preloaded seal in the closed position. A rubber O-ring in a dovetail groove ensures leak tightness. The toggle is fitted with an extension rod which passes from the outside environment to the process environment through a

Figure 1: First attempt at a hermetic bayonet valve using a commercial vacuum valve. A Fermidesigned spool containing chevron seals is mounted to the upper face of the valve. The design is unsuitable since these vacuum valves cannot take pressures greater than 15 psi differential. Also, the threaded actuator is slow and cumbersome to operate in the field.

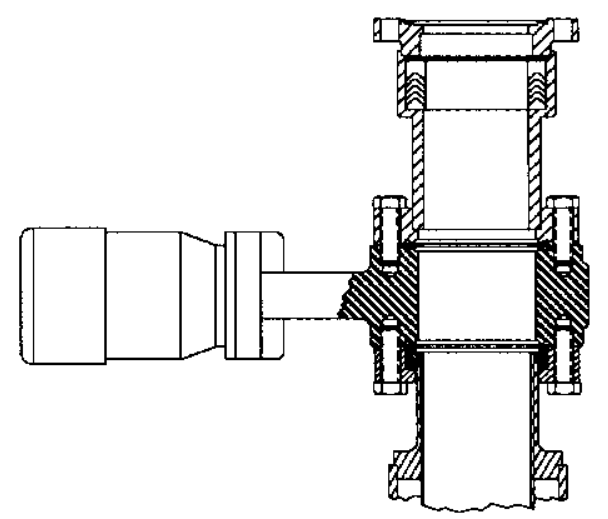




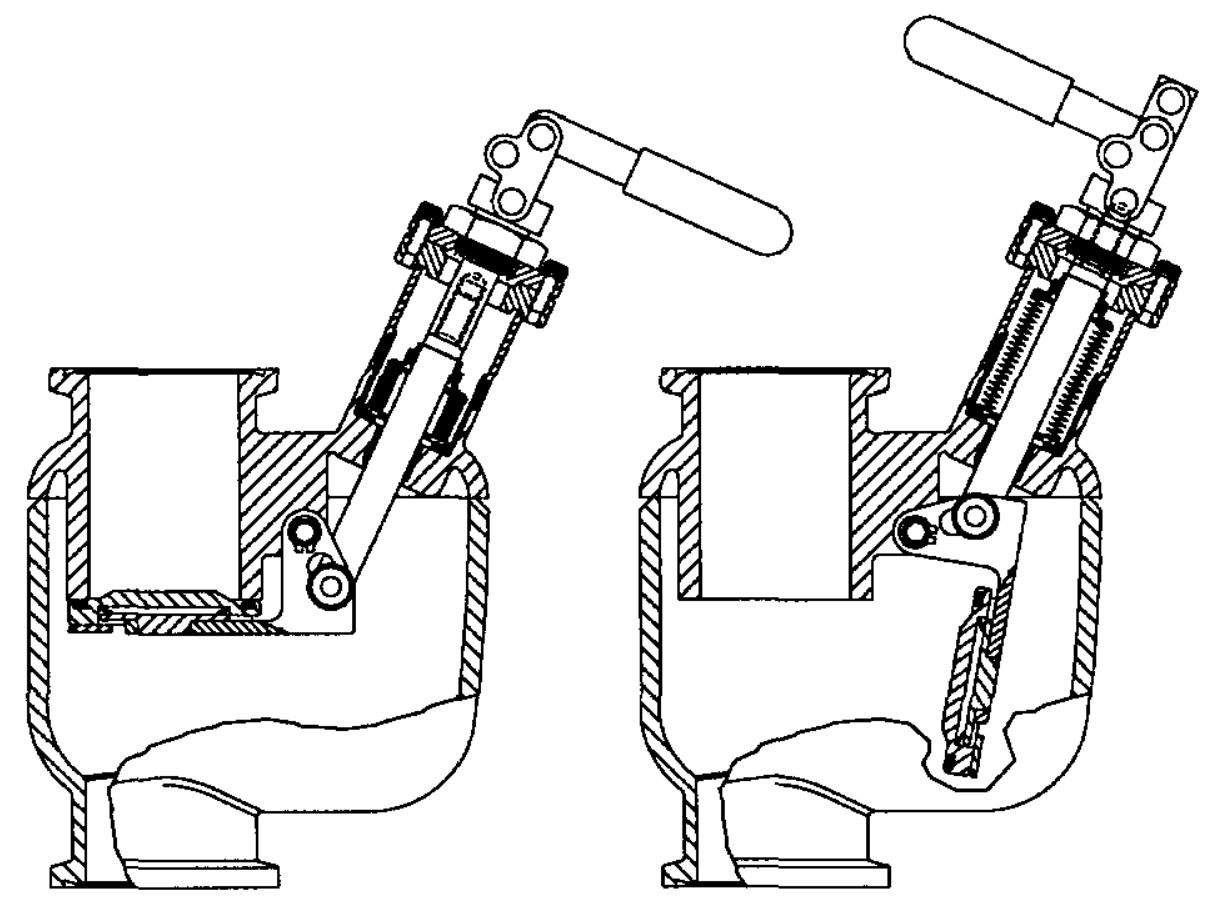

Figure 2: Section views of subatmospheric bayonet isolation valve showing closed and open positions. Handle swing is $180^{\circ}$, sealing disc swing is $80^{\circ}$. The push-pull actuator feeds through a welded bellows.

welded bellows. The bellows is squirm protected by the extension rod and the outer housing. An Iglide T500 plastic bushing made by Igus Corp. guides the extension rod at the lower end. Tolerance stack up requires tight clearances and allowances in the linkage pieces to avoid unwanted "slop" in the mechanism.

\section{Body}

The first prototype was designed using an eccentric reducer as the valve body (Figure 3). This concept was abandoned due to problems with seal disk clearance in the open position and anticipated variation in reducer geometry from piece to piece. Note also the different linkage design in this prototype.

A second prototype is shown in Figure 4. This version incorporated an improved linkage as well as a revised body design. Versions were built up both from split pipe and sheet as well as rolled sheet. The oval shaped, flat sided geometry is appropriate for the small spaces in which these valves reside. These second prototypes performed well although they were expensive to produce and tended to warp during welding, jamming the linkage. This prompted an investigation of casting technology as a means to produce the valve body.

Entec Services, Inc., a consulting firm in Bartonville, IL was awarded a contract to design a valve body suitable for investment casting in $316 \mathrm{~L}$ stainless steel. The 
Figure 3: The original prototype valve. The body is built from an eccentric pipe reducer. The linkage has an additional member, adding complication and potential for slop. The process connections use metal O-ring seals instead of the current copper gasket design.

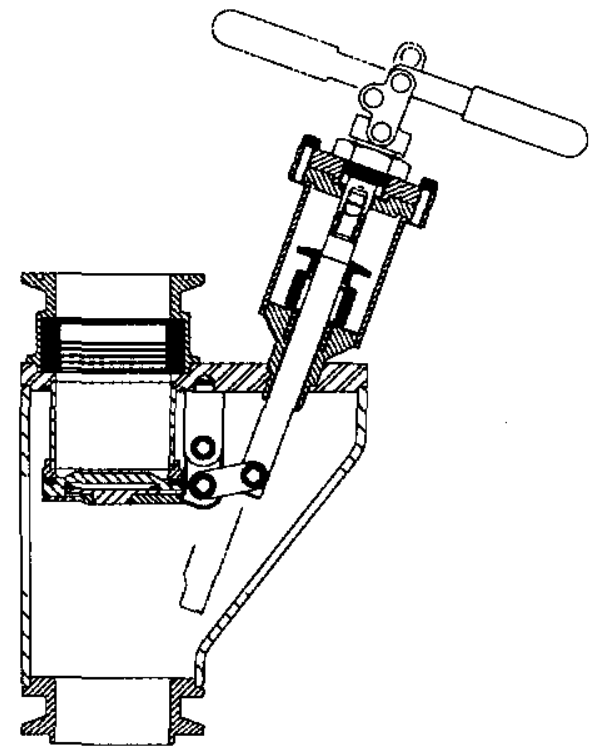

company performed the design using I-DEAS software by SDRC, Inc. of Milford, $\mathrm{OH}$. After several iterations they produced an acceptable design. Finite element analysis was used to determine appropriate wall thicknesses for the design pressure of 300 psid and a safety factor of 4 . Stress results are shown in Figure 5. Once the design was finalized, Entec created a set of plastic models of the body parts using stereolithography equipment from 3-D Systems, Inc. The final design consists of a two piece assembly. The upper piece carries the linkage. The lower piece completes the housing and has the Fermi logo raised on its sides. The plastic models as well as all modeling and analysis data are Fermilab property. Production drawings were created in-house directly from the model data using I-DEAS GeoDraw.

Figure 4: Solid model of the second prototype. This version has the current linkage featuring a slotted connection between flapper arm and toggle extension. The body is a weldment consisting of seven machined pieces. Any warpage during welding can jam the mechanism.

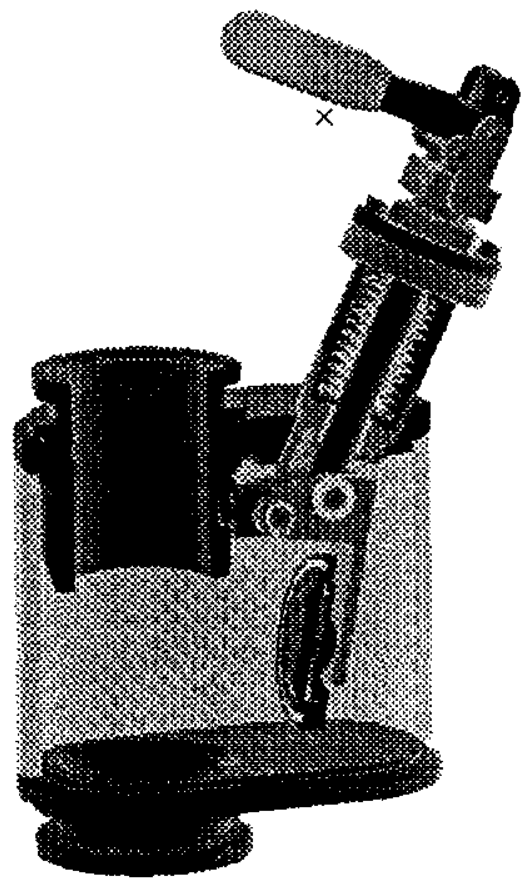




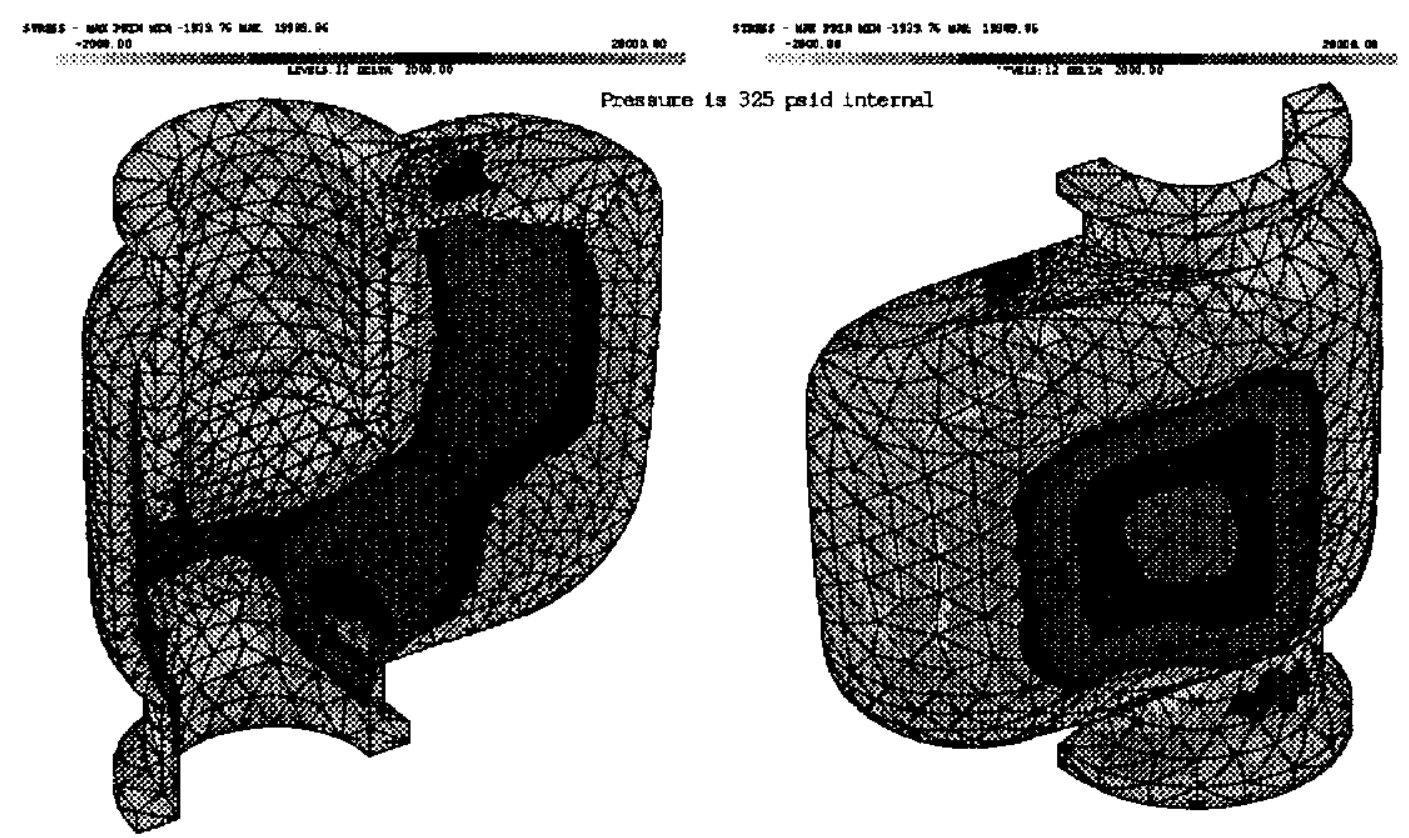

Figure 5: Finite element analysis of the upper and lower body pieces (symmetry invoked) showing stress contours on the inside (left) and outside (right) walls. The model was meshed using solid parabolic tetrahedral elements. Maximum stress of about $20 \mathrm{ksi}$ occurs on the exterior of the side, near the center.

\section{Process Connections}

Our policy is to avoid rubber O-ring seals on subatmospheric components unless they are double seals with guard helium or vacuum. Metal seals are used on these valves at the valve/component and valve/U-tube interfaces. The prototype valves used coated metal O-rings made up with a heavy duty V-band clamp. These units sealed well although the seals were expensive and the highly polished sealing surfaces were prone to damage. The final design uses copper gaskets sandwiched between knife edged flanges (Conflat style). The seal is made up using chain link clamps produced by EVAC of Switzerland. This chain clamp provides clamping force beyond that obtainable with V-band clamps yet it is much faster and easier to make up than a standard bolted flanged connection. This clamp is visible in Figure 6 at the bottom.

Although the knife edges themselves are fairly delicate, they are recessed into the flanges which limits their exposure. The valve is designed with copper gasket connections on both ends. The lower flange is made up to the device that "owns" the valve - this connection will rarely be broken. The upper flange, which connects the valve to the U-tube or removable component, will see all of the service. In the event that the upper flange of the valve is damaged during equipment connection, the entire valve may be swapped out by breaking the lower connection.

\section{Actuator, Feed-through, and Seal}

The valve actuator is a stock toggle clamp produced by the Detroit Stamping Company (De-Sta-Co), used primarily as a retractable locator in fixtures and jigs. 
Figure 6: Photograph of the first valve built from cast components. Machining on the castings for this unit was performed in-house. This unit proved that warping of the upper body part was minimal during welding of the upper and lower parts. Linkage operation was smooth and bind-free after welding. The unit is mass spec leak tight.

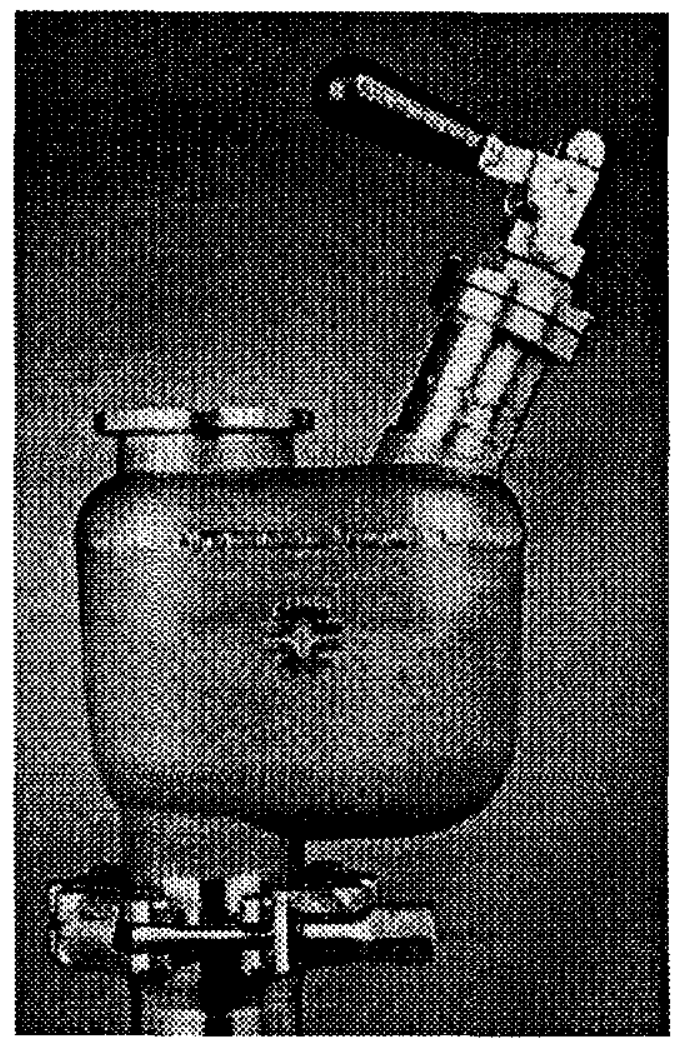

It has a plunger travel of $3 / 4^{\prime \prime}$ over $180^{\circ}$ of lever swing and locks in both the extended and retracted position with up to $200 \mathrm{lb}$ of holding capacity. The stainless steel version used here costs around \$20. In fact, the geometry of the linkage was designed to accommodate this unit's stroke.

The hermetic feed through is designed around a welded bellows supplied by Standard Welded Bellows Co., Windsor Locks, CT. The maximum stroke is 1.14" and the spring rate is $3.6 \mathrm{lb} / \mathrm{in}$. The bellows material is 347 stainless steel. A test unit was fixtured and cycled rapidly between 0 and 350 psig for thousands of cycles without failure. The top end of the bellows welds to the extension rod while the lower end welds to the valve body. The extension rod is guided at the top end by the De-Sta-Co toggle and at the bottom end by an Iglide T500 plastic bushing made by Igus Corp.

The sealing disk rides on the L-shaped flapper arm driven by the extension rod. A Smalley wave spring within the unit allows the disk to "float" on the flapper arm, ensuring alignment and proper sealing force. An O-ring seals the disk to the valve body. Subatmospheric operations only take place when bayonet connections are made up. As a result, the $\mathrm{O}$-ring seal need not be hermetic. The system will always be at positive pressure when bayonet connections are broken and the valve is closed. The O-ring rides in a dovetailed groove for secure seating. However, it can be removed and replaced if necessary without cutting the valve open. When the valve is closed, the sealing disk is exposed to internal pressure equal to that exerted on the valve body. Finite element analyses were used to define the disk profile. Figure 7 shows the analysis results. 

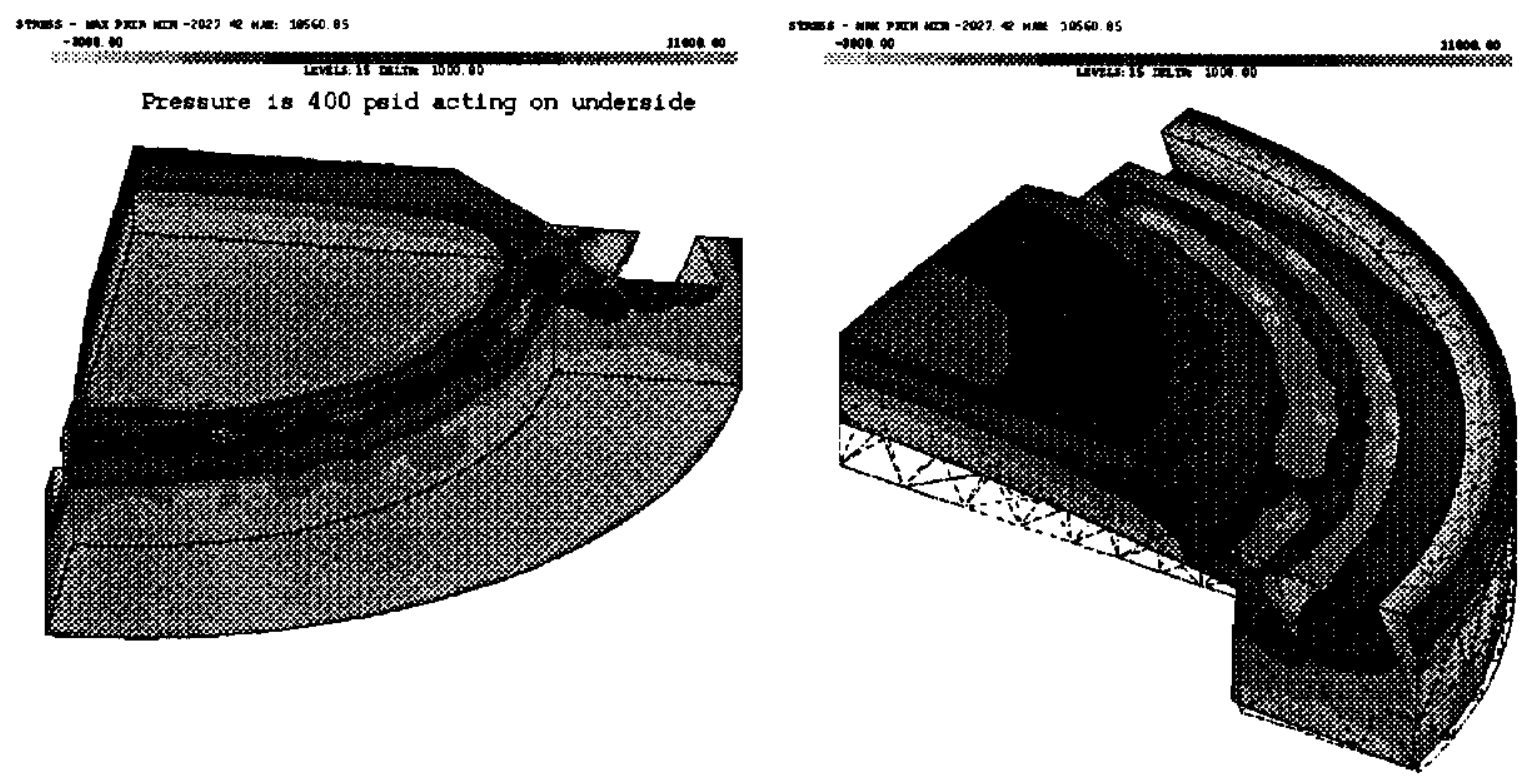

Figure 7: Stress contours on the sealing disk with a $400 \mathrm{psi}$ load on the underside. Maximum stress of about $11 \mathrm{ksi}$ occurs on the underside (left) at the inside corner and at the center of the upper side (right). The right image shows exaggerated deformation along with the original shape in wireframe. Boundary conditions enforce symmetry to model $1 / 4$ of the part. Solid parabolic tetrahedral elements are used.

\section{FABRICATION}

Production drawings were created from the solid models produced by Entec Services. A visit to the American Foundryman's Society booth at the 1992 Design Engineering Show generated plenty of literature on the investment casting process and the companies that do the work. Bids were solicited from several of these companies for a quantity of one hundred each of three different parts of the valve: the upper body, the lower body, and the flapper arm. Parts were to be delivered in the finished, machined condition. The remaining machined parts were contracted for in the usual manner.

The contract for the three cast pieces was awarded to Barroncast, Inc. of Oxford, MI. Delays and setbacks abounded during our association with Barroncast. Ultimately we received four acceptable first article samples of each part. By this time a decision had been made to modify Barroncast's contract. Castings only were purchased from them since they seemed unable to machine the castings to meet specifications. The first article samples we eventually accepted were rough castings. Barroncast was given permission to proceed with the full order, producing 96 more of each piece. A separate contract was competitively awarded to Numerical Precision of Wheeling, IL for the machining work.

Two of the four first article sample sets were machined in-house. This allowed us to verify the design and the suitability of castings for this application. Among dimensional and other criteria, the cast valve needs to weld up without undue warping to preserve linkage alignment. Also, the final assembly must be helium mass spectrometer leak tight to a minimum sensitivity of $1 \times 10^{-9} \mathrm{~atm} \cdot \mathrm{cc} / \mathrm{sec}$, 


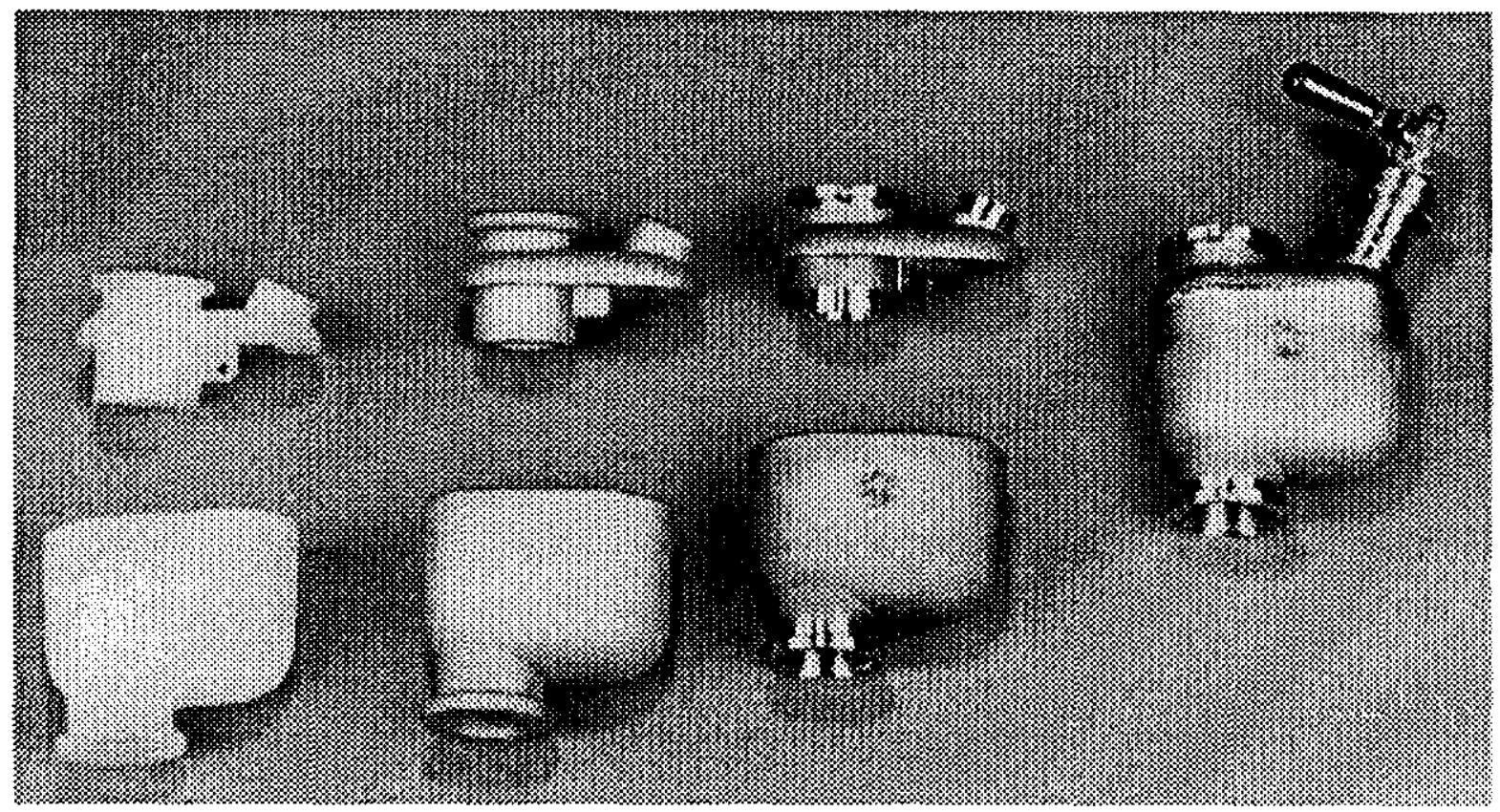

Figure 8: From left to right are shown the Entec plastic models, rough castings, machined castings, and a completed valve. Entec modeled the parts for manufacture as investment castings. Not shown is the flapper arm, an internal member of the linkage which was also produced as a casting.

meaning the castings cannot be porous. Finally, critical surfaces like sealing areas and knife edges need to be reliably machined without encountering voids or other material degradations.

The first article samples provided us sufficient data to authorize production of the full order. Sixty valves will be needed for the upgrade. This leaves forty spares, some of which will no doubt be scrapped due to production errors. This large number of spares is justified since tooling represents over half the cost of the cast pieces. Part inspection took place at TS/Material Control while valve assembly was performed by the AD/Satellite Refrigeration group. Figure 8 shows a progressive sequence beginning with the Entec stereolithography model on the left and ending with a finished valve. Only the upper and lower body pieces are shown.

\section{PERFORMANCE}

Prototype units have functioned without incident for thousands of hours at the "BR" test refrigerator. During this time there have been about ten U-tube pulls involving the valves with the system cold. In each instance the valves operated properly and sealed. The flanged copper gasket connections have served well through dozens of make/break cycles (both warm and cold) without any damage to knife edges. The EVAC chain clamps perform well and are preferred by our field technicians over V-band or bolted and flanged copper gasket connections.

In late January 1993 the Tevatron was shut down for a one week period during which time new valve boxes were installed at the $\mathrm{C} 2$ and $\mathrm{C} 3$ refrigerator buildings. 
Ultimately all valve boxes will be replaced as part of the low temperature upgrade. The prototype hermetic bayonet valves were removed from the test vessel at BR and installed on the new valve boxes bound for $\mathrm{C} 2$ and $\mathrm{C} 3$. We have had no trouble with the valves since their installation.

\section{CONCLUSION}

This valve provides our bayonet connections with a hermetic seal between the Tevatron's subatmospheric helium circuits and the atmosphere. In this manner air contamination of the cryogenic system is prevented. Knife edged flanges with copper gaskets are used for process connections while a welded bellows provides a feed through for the valve actuator. The valve mechanism is a hinged linkage which swings $80^{\circ}$ from an unobstructed open position to a closed position. An O-ring riding in a spring loaded disk seats against a sealing surface machined into the valve body. The linkage is manipulated by a stock toggle clamp which strokes $3 / 4^{\prime \prime}$ over $180^{\circ}$ of handle swing.

Preliminary in-house designs for the valve body were used by a consulting firm to create an optimized computer model of the valve body suitable for manufacture by investment casting. The resulting body design is rated for 300 psig internal pressure and consists of two cast pieces. The upper piece carries the linkage and actuator for ease of assembly. The lower piece welds to the upper with a single circumferential vee-groove butt weld. The geometry of the castings minimizes distortion during welding which could otherwise misalign and jam the linkage. The castings are leak tight and of sufficient quality to allow reliable machining without voids or porosity. Castings for 100 valves have been produced and machined.

\section{REFERENCES}

1. C.H. Rode, Tevatron cryogenic system, in "12th Inter. Conf. of High Energy Accel.", 1983

2. T.J. Peterson and J. Fuerst, Tests of cold helium compressors at Fermilab, in: "Advances in Cryogenic Engineering", Vol. 33, Plenum Press, New York (1988), p. 655

3. R.J. Walker et al., Recent operating experience with the Fermilab central helium liquefier, in: "Advances in Cryogenic Engineering", Vol. 31, Plenum Press, New York (1986), p. 647 